\title{
The Akt pathway in oncology therapy and beyond (Review)
}

\author{
GEORGE MIHAI NITULESCU ${ }^{1}$, MARYNA VAN DE VENTER ${ }^{2}$, GEORGIANA NITULESCU ${ }^{1}$, ANCA UNGURIANU ${ }^{1}$, \\ PETRAS JUZENAS $^{3}$, QIAN PENG ${ }^{3}$, OCTAVIAN TUDOREL OLARU ${ }^{1}$, DANIELA GRĂDINARU ${ }^{1}$, \\ ARISTIDES TSATSAKIS $^{4}$, DIMITRIS TSOUKALAS ${ }^{4}$, DEMETRIOS A. SPANDIDOS $^{5}$ and DENISA MARGINA ${ }^{1}$

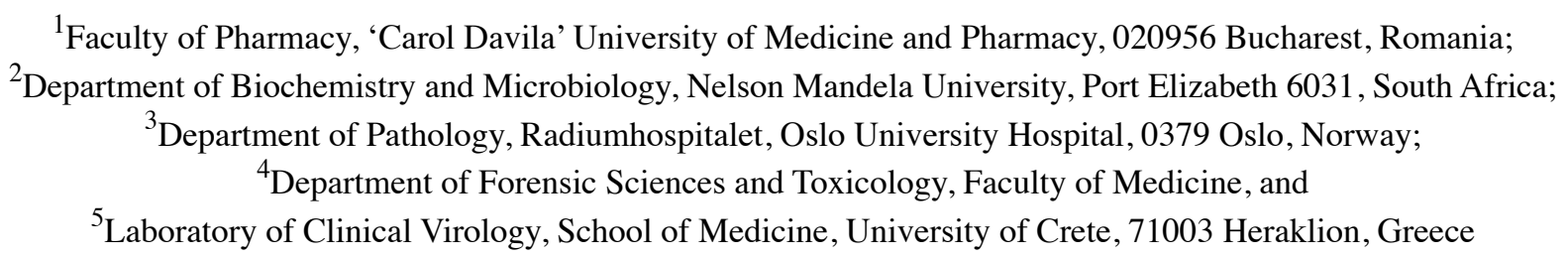

Received August 6, 2018; Accepted October 10, 2018

DOI: $10.3892 /$ ijo.2018.4597

\begin{abstract}
Protein kinase B (Akt), similar to many other protein kinases, is at the crossroads of cell death and survival, playing a pivotal role in multiple interconnected cell signaling mechanisms implicated in cell metabolism, growth and division, apoptosis suppression and angiogenesis. Akt protein kinase displays important metabolic effects, among which are glucose uptake in muscle and fat cells or the suppression of neuronal cell death. Disruptions in the Akt-regulated pathways are associated with cancer, diabetes, cardiovascular and neurological diseases. The regulation of the Akt signaling pathway renders Akt a valuable therapeutic target. The discovery process of Akt inhibitors using various strategies has led to the identification of inhibitors with great selectivity, low side-effects and toxicity. The usefulness of Akt emerges beyond cancer therapy and extends to other major diseases, such as diabetes, heart diseases, or neurodegeneration. This review presents key features of Akt structure and functions, and presents the progress of Akt inhibitors in regards to drug development, and their preclinical and clinical activity in regards to therapeutic efficacy and safety for patients.
\end{abstract}

Correspondence to: Professor Denisa Margina, Faculty of Pharmacy, 'Carol Davila' University of Medicine and Pharmacy, 6 Traian Vuia, 020956 Bucharest, Romania

E-mail: denisa.margina@gmail.com

Professor Aristides Tsatsakis, Department of Forensic Sciences and Toxicology, Faculty of Medicine, University of Crete, 71003 Heraklion, Greece

E-mail: tsatsaka@uoc.gr

Key words: phosphoinositide 3-kinase/protein kinase B/mammalian target of rapamycin pathway, apoptosis, cancer, neurodegenerative disease, diabetes, clinical trial, repurposing drugs, natural products

\section{Contents}

1. Structure and function

2. Akt in malignant disease

3. Neurological diseases

4. Insulin signaling and diabetes

5. Involvement of Akt in cardiovascular events

6. Pulmonary fibrosis

7. Akt in inflammation and autoimmune diseases

8. Repurposing studies

9. Natural products targeting the Akt pathway

10. Akt inhibitors in clinical studies

11. Conclusions

\section{Structure and function}

Akt is a serine/threonine kinase previously known as protein kinase $\mathrm{B}$ (PKB), consisting of three isoforms (Akt1, Akt2 and Akt3), with a crucial role in major cellular functions including cell size, cell cycle progression, regulation of glucose metabolism, genome stability, transcription, protein synthesis and neovascularization. Akt promotes cell survival by mediating the cellular growth factors and blocking apoptosis by the inactivation of pro-apoptotic proteins (1-5).

From a structural point of view, Akt/PKB is characterized by its similarity to protein kinases $\mathrm{A}$ (PKA) and $\mathrm{C}$ (PKC), as well as to the retroviral oncoprotein viral akt (v-akt) (6-9). Structurally, Akt comprises three domains: An amino-terminal (N-terminal), a central and a carboxyl-terminal fragment (C-terminal). The N-terminal domain, a pleckstrin homology (PH) one, consists of 100 amino acids and is similar to others found in 3-phosphinositide binding molecules, interacting with membrane lipid products such as phosphatidylinositol $(3,4,5)$-trisphosphate (PIP3) and phosphatidylinositol 4,5-bisphosphate (PIP2). The kinase domain is highly similar to the AGC protein kinases sharing a regulatory threonine residue, Thr308. The phosphorylation of this residue activates Akt. The $\mathrm{C}$-terminal groove consists of 40 amino acids forming a hydrophobic region, containing a regulatory serine residue, $\operatorname{Ser} 473$ (6). 
Upstream of molecular signaling pathways of Akt, are found systems generating PIP3 as an effect of the action of phosphoinositide 3-kinase (PI3K) (10-12). Three types of intracellular lipid kinases are described (class I, II and III) based on their structure and substrate selectivity. Class I is divided into class IA (PI3K $\alpha, \beta$ and $\delta$ ) and class IB (PI3K $\gamma$ ). The PI $3 \mathrm{~K} \gamma$ kinases are heterodimers with a catalytic subunit $(\mathrm{p} 110 \alpha, \beta, \gamma$ or $\delta$ ) and a regulatory subunit (p85 $\alpha, \beta$ or $\gamma$ ). Class IA PI3Ks (PIK3CA, PIK3CB and PIK3CD), are constituted from a p110 catalytic unit and a 85 regulatory one, and are the most important isoforms in cancer studies. PI3Ks are activated by different agents; PI3K $\alpha, \beta$ and $\delta$ are activated when the extracellular ligands bind to one of the transmembrane glycoproteins with enzymatic activity called receptor tyrosine kinases (RTKs), while PI3K $\gamma$ is activated by G-protein-coupled receptors (GPCRs) and by the RAS family of GTPases (13-15).

The Akt cascade is activated by various signals including RTKs, integrins, B and T cell receptors, cytokine receptors and GPCRs throughPIP3 produced by PI3Ks. Akt is not directly activated by PIP3, which alters Akt configuration by binding to its $\mathrm{PH}$ region and recruits it to the plasma membrane allowing phosphoinositide-dependent kinase-1 (PDK1) to phosphorylate at $\mathrm{Thr} 308$ residue in the kinase domain $(6,16-18)$. The full activation of Akt requires a second phosphorylation at regulatory Ser473 (Fig. 1).

A number of kinases are known to be capable of phosphorylating Akt at Ser473. These include PDK-1, integrin-linked kinase (ILK) or an ILK-associated kinase and Akt itself (19). Binding proteins such as actin, Erk1/2, Hsp90, Hsp27 or Posh have been found to regulate the activity of Akt (20). Members of the PI3K-related kinase (PIKK) family, including DNA-dependent protein kinase (DNA-PK), can also phosphorylate Akt at $\operatorname{Ser} 473(2,10,11)$.

Phosphorylated Akt contributes to the phosphorylation of different proteins located either in the plasma membrane, in the nucleus or the cytosol, supporting cell growth and survival, among other cellular effects. Akt phosphorylates a large number of targets on RxRxxS/T consensus motifs (21). Such downstream targets of Akt phosphorylation are PRAS40, a component and regulator of mTOR complexes, the actin-associated protein palladin, the cell cycle inhibitors p21 (Cip1) and p27, and vimentin, all enhancing tumor motility, invasion and metastasis growth $(22,23)$.

One of the key elements of the Akt network is the serine/threonine protein kinase known as mammalian target of rapamycin (mTOR). mTOR can form two functionally distinct multiprotein complexes, mTOR complex 1 (mTORC1) by joining with regulatory-associated protein of target of rapamycin (RAPTOR) and mammalian lethal with SEC13 protein 8 (mLST8). mTOR complex 2 (mTORC2) contains the protein RICTOR which is insensitive to rapamycin, mLST8 and mammalian stress-activated protein kinase interacting protein (mSIN1) $(24,25)$. mTOR is a downstream member of Akt and a key regulator of cell growth and metabolism, but also an activator, mTORC2 directly phosphorylating Akt's hydrophobic motif Ser473 (26). Ser473 phosphorylation enhances Akt kinase activity and facilitates the Thr308 phosphorylation by PDK1 (27).

The Akt pathway intercedes cell growth and survival by influencing the tuberous sclerosis complex (TSC) $1 / 2$ along mTORC signaling and, respectively, by inhibiting pro-apoptotic proteins or signals $(22,23,28,29)$. Activated Akt reduces the formation of TSC1/2 and thus blocks the activation of Rheb, a RAS family protein that activates mTORC1, which in turn, induces the phosphorylation of ribosomal protein $\mathrm{S6}$ kinase (S6K) and the eukaryotic translation initiation factor 4E-binding protein 1 (4E-BP1). Phosphorylated 4E-BP1 stimulates the release of eukaryotic translation initiation factor $4 \mathrm{E}$ (eIF4E). Both S6K and eIF4E promote protein translation and cell proliferation (30-32). The phosphorylation of TSC2 by Akt can dissociate the TSC1-TSC2 complex, thereby activating mTORC1. When mTORC1 is activated, autophagy is inhibited (33).

Akt directly regulates cell survival by inhibiting pro-apoptotic signals, such as Bad and Forkhead box O (FOXO) transcription factors. FOXO proteins activate or suppress the transcription of target genes through a highly conserved winged helix DNA-binding domain and are regulated by several posttranslational modifications, such as phosphorylation, acetylation and ubiquitination (34). FOXOs activate the transcription of target genes to promote cell cycle arrest, cell death and cellular oxidative stress to maintain metabolic stability. Akt phosphorylates and inactivates the FOXO transcription factors, resulting in their nuclear exclusion and degradation in the cytoplasm, triggering cell survival. The decreased activity of FOXO blocks the transcription cyclin-dependent kinase (CDK) inhibitors p27 and p21, resulting in cell cycle progression $(35,36)$. It also inhibits the extrinsic apoptotic pathway mediated by the transcription of proapoptotic factors such as Fas ligand (FasL) and TNF-related apoptosis-inducing ligand (TRAIL) $(16,37)$.

There are some systems responsible for turning off Akt. Akt is dephosphorylated by protein phosphatase $2 \mathrm{~A}(\mathrm{PP} 2 \mathrm{~A})$ and the $\mathrm{PH}$ domain leucine-rich repeat-containing protein phosphatases (PHLPP). PP2A preferentially dephosphorylate Akt at Thr308 residue, but under certain conditions it can also dephosphorylate the Ser473 residue (38). Although PHLPP1 and PHLPP2 both dephosphorylate the Ser473 residue, they differentially stop the signaling by regulating distinct Akt isoforms; PHLPP1 specifically modulates the phosphorylation of HDM2 and glycogen synthase kinase (GSK)-3 $\alpha$ by Akt2, whereas PHLPP2 regulates the phosphorylation of p27 by Akt3 (39).

Phosphatase and tensin homolog (PTEN) is the most important negative regulator of Akt function and its metabolic downstream effects. The phosphatase activity of PTEN functions as an antagonist of PI3K, dephosphorylating PIP3 in position 3 ' to form PIP2 $(40,41)$. Mutations leading to the amplification of genes in the receptor-PI3K pathway, and also the loss of function of PTEN are found frequently in cancer tissues, resulting in pathologically enhanced PI3K signaling and the loss of cell growth control by decreased apoptosis (36).

The PI3K/Akt/mTOR pathway is dysregulated in different diseases, such as solid tumors, immune-mediated disease, idiopathic pulmonary fibrosis, cardio-vascular disease, metabolic impairments such as diabetes mellitus, and constitutes a promising therapeutic target $(29,42,43)$.

\section{Akt in malignant disease}

The PI3K/Akt pathway has been intensively investigated in cancer due to its significant role in cell survival and anti-apoptotic mechanisms. Multiple pathogenic mechanisms, including 


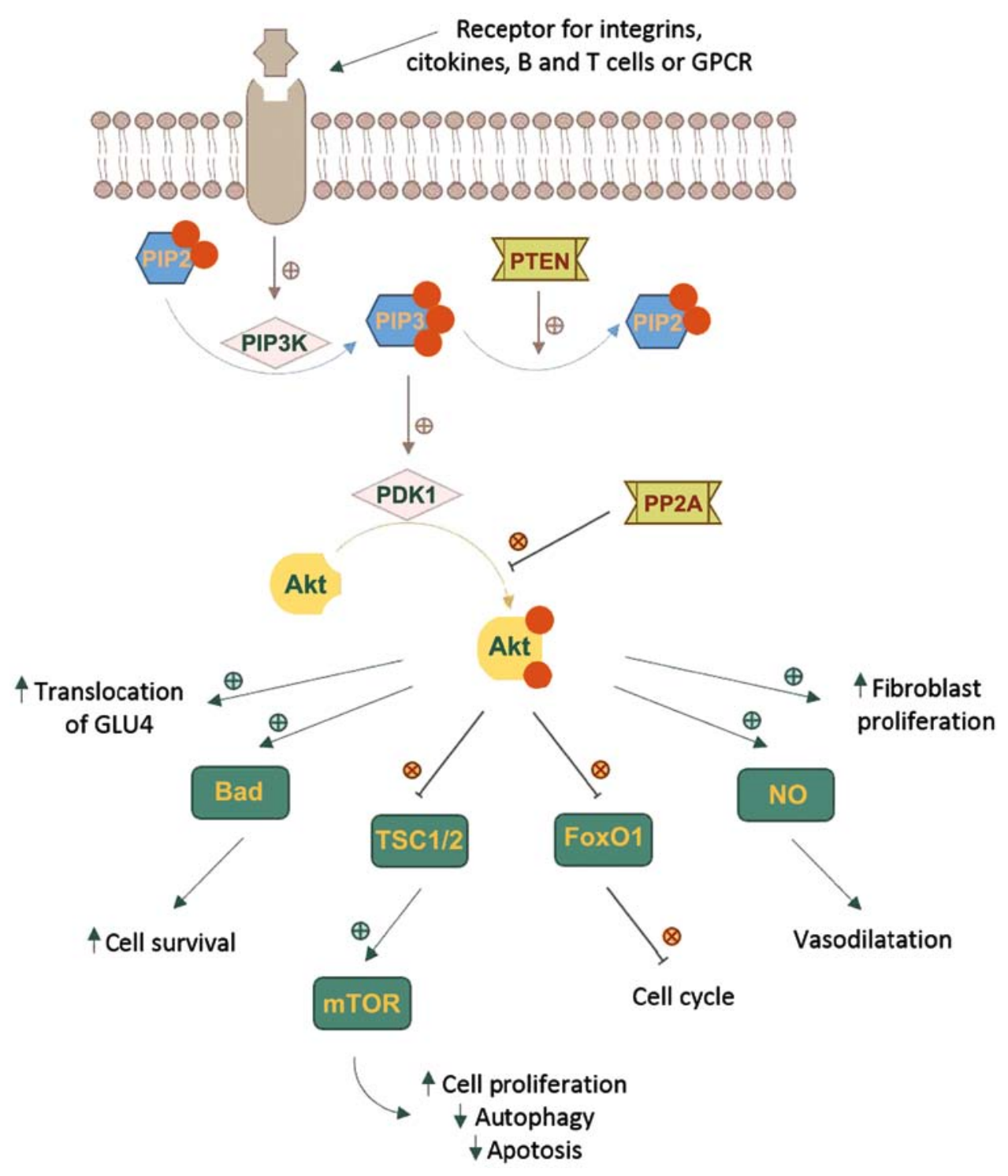

Figure 1. Regulation and downstream effects of the Akt signaling pathway.

the loss of PTEN, mutations that activate the catalytic subunit of PI3K, the activation of RAS and growth factor receptors, or tge amplification of the genes encoding PI3K or Akt can lead to Akt hyperactivation in cancer cells (44).

Studies have proven that the Akt signaling pathway frequently malfunctions in various types of cancer and, in some cases, is associated with tumor aggressiveness. Many types of human cancer are associated with the upregulation of Akt. Anomalies of Akt genes were described for a varie ty of human cancers; Akt1 gene amplifications have been reported in gastric carcinoma, glioblastomas and gliosarcomas, whereas Akt2 amplification has been identified in head and neck squamous cell carcinoma, pancreatic, ovarian and breast cancers (45). Several studies have reported upregulated Akt 3 expression in androgen resistant prostate cancer cells, estrogen receptor-deficient breast cancer cells, and in primary ovarian cancers $(46,47)$.

Several of the proteins involved in the Akt signaling pathway (eIF4E, periostin, both the $\mathrm{p} 110 \alpha$ and $\mathrm{p} 85 \alpha$ subunits of PI3K), when overexpressed, can function as oncoproteins, while the ones involved in quenching this pathway (PTEN, FOXO and TSC1/2) may constitute tumor suppressors $(6,16,48)$. PTEN activity can be impaired by various mechanisms, including but not limited to, somatic mutations, homozygous deletions, epigenic silencing through gene promoter methylation, or post-transcriptional modifications (49). PTEN somatic mutations are described in a large percentage of human cancers, with the highest frequency in endometrial cancers, glioma, colorectal cancers, melanoma and prostate cancers (45).

Autophagy is one mechanism through which cells can move towards programmed cell death. Literature data indicate that there are multiple links between impaired autophagy and cancer, autophagy being a mechanism of tumor suppression. The Akt activated mTOR signaling pathway negatively regulates autophagy; this constitutes a pharmacological target, as anticancer molecules blocking the PI3K/Akt/mTOR signal promote autophagy progression, and also reduce angiogenesis $(33,50)$. In this context, recent research has proven that anti-inflammatory molecules (aspirin, celecoxib, meloxicam, or indomethacin) may be useful tools in dealing with tumors as they have the ability to interact with these signaling pathways (50-52).

In addition, the overexpression of Akt is linked to resistance to chemotherapeutic agents such as cisplatin, methotrexate or 
paclitaxel (53). Cisplatin-induced DNA damage causes the phosphorylation of BAD via Akt, suppressing its apoptotic effect (54). This observation can be capitalized as a promising strategy for synergic cancer therapy. The Akt inhibitor, MK-2206, has been shown to improve the effectiveness of cisplatin in the gastric cancer cell line, AGS (55), and against the ovarian cancer cell line, SKOV3 (56). MK-2206 demonstrated similar synergic effect in combination with paclitaxel in SKOV3 cells (56). A low PTEN expression is a good predictor of poor responses to human epidermal growth factor receptor (HER2) antagonist therapies and it has been hypothesized that Akt inhibitors can overcome the development of resistance $(57,58)$.

The importance of Akt in cancer pathologies renders it a much pursued target for anticancer therapy, and multiple drug discovery programs focus on finding selective and potent inhibitors. One of the mains issues counteracting drug design efforts consists of achieving selectivity over structurally similar protein kinase, particularly towards the AGC kinase family. The existence of three isozymes with distinct function, tissue distribution and ligand affinity also obstructs the research. The target-based drug development of Akt-specific and isoform-selective inhibitors using the catalytic domain has been predicted to be difficult due to high sequence homology, determining alternative and novel approaches to identify allosteric inhibitors $(29,44)$.

In an extensive review, we proposed a new classification of the Akt inhibitors based on the binding mechanism related to adenosine triphosphate (ATP) and on their main chemical scaffold (29). The Akt inhibitors advanced from ATP-competitive agents to ATP non-competitive inhibitors binding to allosteric sites in order to solve the high structural similarity in the catalytic domain between Akt isoforms and considerable structural analogy to the AGC kinase family (29,59).

The majority of Akt inhibitors targeting the ATP binding site are non-selective against the three isoforms, and poorly selective against structurally similar kinases (60). Akt1-3 share a high ATP-binding site homology with S6K1 (84\%), PKA (81\%), PKC (78\%), SGK (78\%),PRKX (75\%), PKN1 (75\%) and Aurora A (72\%) (43). The ATP-competitive inhibitors of Akt can be chemically described as isoquinoline-5-sulfonamides, azepane derivatives, aminofurazans, heterocyclic 6-5 fused rings, phenylpyrazoles, thiophene carboxamides and thiazole carboxamides (29).

The ATP non-competitive Akt inhibitors are allosteric modulators, the binding mechanism offering important advantages, as greater specificity, reduced side-effects and lower toxicity (43). Chemically, they are categorized as 2,3-diphenylquinoxaline and analogs, alkylphospholipids, derivatives of indole-3-carbinol, sulfonamides, thiourea deratives and purine derivatives. A special class of ATP non-competitive are the irreversible inhibitors that interact covalently with the enzyme (29).

Current pre-clinical and clinical data suggest that the use of an intermittent high-dose posology is more effective than a continuous low dose by daily administration. The high doses are required for induction of apoptosis and pauses can overcome the toxicological risks. Also, data shows a delay in treatment resistance mechanisms. The combination with other targeted therapeutic agents further enhances the antitumor activity of Akt inhibitors $(42,61)$.

\section{Neurological diseases}

Early observation associated with increased amounts of glutamate with excitotoxicity and neural cell death have opened and facilitated the development of treatments for glutamate-related disorders, such as Alzheimer's disease (AD), parkinsonism, epilepsy, or multiple sclerosis (62). The overstimulation of glutamate receptors (GluRs) and other post-synaptic signaling components results in excitotoxicity. It is considered that $N$-methyl-D-aspartate (NMDA) subtypes play a major role, and other GluR subtypes such as acid 2-amino-3-(3-hydroxy-5-methylisoxazol-4-yl)propionic (AMPA) or kainate receptors play a critical role in the excitotoxic neuronal cell death process (63). Reversely, the stimulation of metabotropic GluR1 (mGluR1) exerts neuroprotectives effect by reducing nerve cell death induced by exposure to NMDA $(64,65)$.

$\mathrm{AD}$ is a progressive neurodegenerative disease characterized by the alteration of memory and cognitive functions, and is caused by the damage of neurons. Post-mortem histopathological examinations have revealed extracellular amyloid $\beta(\mathrm{A} \beta)$ plaques and intracellular neurofibrillary tangles as hallmark lesions of AD. It has been demonstrated that an elevated GSK-3 $\beta$ activity is directly linked to increased levels of $\mathrm{A} \beta$ production and deposits, tau hyperphosphorylation and the formation of neurofibrillary tangles $(66,67)$. GSK- $3 \beta$ is rendered inactive when it is phosphorylated at Ser9 by phosphorylated Akt, and therefore an upregulation of Akt may contribute to a decrease in AD progression. This hypothesis is associated with the neurotoxic effect of wortmannin, an inhibitor of PI3K that induces tau hyperphosphorylation similar to that observed in AD following incubation in hippocampus slice culture. Lithium chloride, a GSK- $3 \beta$ inhibitor, prevents the neurotoxic effects of wortmannin (68).

The treatment of hippocampal and cerebral cortical cell cultures with toxic doses of NMDA has been shown to cause a significant decline in phosphorylated Akt levels and phosphorylated GSK-3 $\beta$, without caspase-3, caspase-7, or poly(ADP) ribose polymerase (PARP) cleavage; the total levels of Akt and GSK-3 $\beta$ were not shown to be affected (69). Excessive NMDA activity has been demonstrated to cause excitotoxicity, promoting cell death, a probable mechanism of neurodegeneration in $\mathrm{AD}$, in agreement with the GSK- $3 \beta$ hyperactivation hypothesis (70). The role of Akt hypofunction in AD has been demonstrated by several studies on PTEN regulation $(71,72)$. Okadaic acid leads to PTEN activation in SH-SY5Y cells associated with an increase in tau phosphorylation, an effect that can be blocked by PTEN knockdown (73).

The elevation of Akt activity has emerged as a effective strategy with which to prevent progressive neuronal death in neurological diseases. The $4 H$-chromene-3-carboxylate derivative, SC79, was identified as a specific pan-Akt activator. SC79 specifically binds to the PH domain of Akt, leading to a conformation favorable for phosphorylation by upstream protein kinases, without altering total Akt levels. The treatment of cultured cortical neurons with SC79 has been shown to markedly enhance Akt phosphorylation and reduce neuronal death elicited by glutamate excitotoxicity in hippocampal neurons. SC79 effectively reduced the neocortical lesion size by $35 \%$ after a single dose of $0.04 \mathrm{mg} / \mathrm{g}$ of body weight in a murine ischemic stroke model (74). 
The inhibition of PTEN function in conditions associated with neurodegeneration, tissue injury or ischemia may be a valuable pharmacological intervention with which to activate Akt function. Bisperoxovanadium compounds are reversible and relatively specific small PTEN inhibitors, with nanomolar affinity and have been experimentally explored as a potential therapeutic approach in AD and other neurological diseases (75).

Parkinson's disease (PD) is a chronic and progressive neurodegenerative disorder characterized by the premature death of dopaminergic neurons in the substantia nigra (76). Oxidative stress is a major cause of PD pathogenesis, inducing neuronal cell death and apoptosis by intracellular calcium overload, lipid peroxidation, DNA damages and excitotoxicity.

The activation of Akt has been shown to efficiently protect neurons or neuronal cells from oxidative stress and is an established target of drug design in PA. Pre-treatment of human dopaminergic neuronal cells with the specific Akt activator, SC79 $(10 \mu \mathrm{M})$, was previously shown to markedly attenuate hydrogen peroxide-induced toxicity. The neuroprotective effect of SC79 was abolished by Akt inhibitors (77).

Sulfuretin, a trihydroxyaurone isolated from the bark of the lacquer tree (Toxicodendron vernicifluum), was previously shown to significantly decrease apoptotic cell death induced by the 1-methyl-4-phenylpyridinium $\left(\mathrm{MPP}^{+}\right)$in an experimental model of PD. Sulfuretin reduced caspase-3 and PARP activity accompanied by a reduction of intracellular reactive oxygen species (ROS) production and recovered the normal mitochondrial membrane potential. The mechanism involved the augmentation of the phosphorylation of Akt, GSK-3 $\beta$ and Erk pathway, confirmed by the disappearance of the cytoprotective effects of sulfuretin following the administration of PI3K/Akt and Erk inhibitors (78). Vitexin, a glucoside derivative of apigenin and several other flavonoids had similar protective effects on cell and mouse models of PD (79).

\section{Insulin signaling and diabetes}

Akt is involved in the insulin signaling pathway; the activation of the insulin receptor triggers a phosphorylation cascade, initiated by receptor autophosphorylation and the activation of insulin receptor substrate proteins (IRS-1 and IRS-2), recruiting PI3K that phosphorylates PIP2 to PIP3. Membrane-anchored PIP3 activates Akt, thus contributing to the translocation of the glucose transporter 4 (GLUT4) at the membrane level $(80,81)$. Similarly to insulin, members of the family of insulin-like growth factors (IGF) activate PI3K to produce PIP3, which, in turn, recruits two protein kinases to the plasma membrane via their PH domains Akt and PDK1, leading to Akt activation (81). Akt 2 and its downstream effectors control the insulin-stimulated translocation of GLUT4 to the plasma membrane. The most important are AS160, a Rab GTPase-activating protein, CDP138, a C2 domain-containing phosphoprotein, and an actin-capping protein, tropomodulin $3(82,83)$.

The downstream steps determining the effects of insulin on target tissues, including glucose uptake in skeletal muscle and adipose tissue, and hepatic gluconeogenesis are controlled by Akt2. Glycogen synthesis is regulated by Akt phosphorylation and the inactivation of GSK-3 $\beta$, resulting in glycogen synthase activation (81).
Akt2 is highly expressed in insulin-responsive tissues and is an important regulator of glucose metabolism. The deletion of $\mathrm{Akt} 2$ in knockout mice was previously shown to result in insulin resistance, hyperinsulinemia and glucose intolerance, whereas Akt1 or Akt3 knockout mice have a normal glucose metabolism (84). Leptin was shown to increase insulin sensitivity in Akt-deficient mice (85). Consistent with these studies, defects in the kinase domain of Akt2 are associated with insulin resistance and diabetes in humans (86). Conversely, an activating mutation of Akt2 in humans was reported and was shown to be associated with severe insulin-independent hypoglycemia and asymmetric overgrowth (87) and a lower risk of diabetes was observed in individuals with PTEN haploinsufficiency (81).

Insulin is also a potent neurotrophic factor and the activation of the insulin receptors, highly expressed in sensory neurons, enhances axon growth through the stimulation of the PI3K/Akt pathway and counteracts diabetic polyneuropathy symptoms. Recent research considers that an important strategy for reversing the neuropathic deficits of diabetic neuropathy may be either the activation of intrinsic PI3K/Akt signaling or the inhibition of the PTEN effect $(80,81)$. As in the case of $\mathrm{AD}$, various vanadium compounds have been proven to reduce blood glucose in diabetic rats $(88,89)$. Although he systemic long-term PTEN pharmacological inhibition is likely to promote cancer, it is possible that a tissue-specific inhibition may be beneficial in type 2 diabetes treatment (75).

Another strategy which can be used to enhance Akt signaling to potentially overcome insulin resistance, is the inhibition of PHLPP. The strategy is enforced by the observation that the levels of PHLPP1 are highly elevated in the skeletal muscle of obese humans, and are associated with the increased body mass index and insulin resistance. Additionally, PHLPP1 mRNA levels are elevated in muscle cells from diabetic patients (40). Two specific inhibitors of PHLPP2 were identified in a virtual screening coupled with biochemical assays, a derivative of aminoanthraquinone and a diazenyl derivative of salicylic acid. Both compounds inhibit the dephosphorylation of Akt on Ser473 at micromolar doses and have the potential to improve insulin secretion (90).

Statins are HMG-CoA reductase inhibitors intensively used to reduce cholesterol levels in a wide range of patient populations. Several studies have demonstrated that statin use is associated with an increased risk of developing type 2 diabetes mellitus by the reduction of insulin secretion and the induction of insulin resistance. These effects are produced by decreasing GLUT-4 levels and the inhibition of GSK-3 $\beta$, p38 MAPK and Akt phosphorylation $(91,92)$. Statin treatment profoundly affects signaling through Akt in several cell models. Simvastatin and atorvastatin have been shown to inhibit Akt activation and to be cytotoxic in mouse myoblast cell line at doses of $10 \mu \mathrm{M}$, while for rosuvastatin the dose is $50 \mu \mathrm{M}(92,93)$. These studies highlight the importance of the Akt signaling pathway in both statin-induced myotoxicity and diabetes, as well as the anticancer effects of statins.

\section{Involvement of Akt in cardiovascular events}

In a number of physiological and pathological cardiovascular processes, such as vessel remodeling, atherosclerosis and 
vascular injury, apoptotic cell death was identified as a major common factor leading to a close analysis of the Akt network involvement. Akt activation stimulates downstream anabolic signaling, favoring cell growth, proliferation and survival; this is a desired effect for cardiac cells, whose metabolic improvement following the stimulation of Akt may also alleviate cardiac cellular damage (94).

Aktl plays an important role in the regulation of cardiac hypertrophy and angiogenesis, as the absence of Akt1 leads to severe atherosclerosis and occlusive coronary arterial disease, associated with significant reduction in NO production and endothelial cell viability. It was observed that atherosclerosis results in the reduction of Akt expression and phosphorylation in plaque intimal vascular smooth muscle cells and an increased expression of active FOXO3a. An ectopically activated Akt was used to demonstrate that Akt activation is sufficient for the survival of vascular smooth muscle cells in response to oxidative stress. The PI3K/Akt pathway can stimulate NO production by endothelial cells and increase the synthesis of prostacyclin, thus leading to vasodilation and retarding atherogenesis (94-96).

$\mathrm{Akt} 2$ is also involved in multiple functions in the cardiovascular system due to its abundance in insulin-responsive tissues. Mice lacking Akt2 present with hyperglycemia and dyslipidemia with high levels of triglycerides and cholesterol, although the absence of Akt2 does not influence the progression of atherosclerosis in mice (95).

The PI3K/Akt pathway is involved in cardioprotection by various mechanisms, such as the heat shock protein (HSP) 90-mediated protection of cardiomyocytes subjected to hypoxia or the estrogen receptor (97). Studies using mouse models have shown that a reduced activation of the PI3K p110 $\alpha$ catalytic subunit increases the risk of atrial fibrillation. Conversely, the augmentation of Akt activity in murine models of heart failure has been shown to improve cardiac function $(98,99)$. These findings explain why some anticancer protein kinase inhibitors, such as ibrutinib and nilotinib, increase the occurrence of atrial fibrillation and drug-induced long QT syndrome $(98,100)$.

It is hypothesized that the PI3K/Akt signaling pathway may provide a solution for addressing proarrhythmia by regulating cell proliferation and survival through the PIP3 activation of downstream signals; nevertheless, an increased activity of PI3K/Akt signaling may lead to cancer development (100).

\section{Pulmonary fibrosis}

Idiopathic pulmonary fibrosis (IPF) is a chronic, progressive lung disease, one of the most common types of interstitial pneumonia associated with high morbidity and mortality. In normal lung fibroblasts, the interaction with type I collagen, suppresses the PIP3K/Akt pathway, through the activation of PTEN, thus inhibiting cell proliferation and promoting fibroblast apoptosis. Pathologically, in fibroblasts from patients with IPF, PI3K/Akt activity is enhanced due to the suppression of PTEN, rendering the cells highly proliferative and resistant to apoptosis (101-103). It has been demonstrated that the low activity of PTEN is caused by the decline of the caveolin-1 and FOXO3a levels $(104,105)$.

Previously, a model of pulmonary fibrosis was used in rats following the intratracheal administration of bleomycin, and it was demonstrated that the high levels of phosphorylated Akt were involved in the progression of pulmonary fibrosis and contributed to fibrogenesis (106). Tubastatin, a known histone deacetylase 6 (HDAC6) inhibitor, has been shown to protect mice against bleomycin-induced fibrosis by decreasing Akt phosphorylation and increasing Akt association to PHLPP, independent of its HDAC6 effects (107).

\section{Akt in inflammation and autoimmune diseases}

Autoimmune diseases occur when the immune system mistakenly recognizes self-tissues as foreign and triggers an immune response. The autoreactivity of the immune system is multifactorial and may lead to pathogenic autoimmunity and is related autoimmune diseases (108). Although the exact mechanisms of the pathogenesis of autoimmune diseases remain unclear, the over activation and abnormal function of T cells, B cells and myeloid cells has been extensively studied (109-111). Systemic lupus erythematosus (SLE) is a systemic autoimmune disease characterized by the high hyperactivity of $\mathrm{T}$ cells and $\mathrm{B}$ cells, which result in the production of antinuclear, anti-double-stranded DNA and anti-glomerular antibodies, nephritis, renal failure and mortality (112).

Patients with SLE are characterized by the activation of mTORC1 and reduced mTORC2 levels, promoting the expression of pro-inflammatory cytokines, and the deletion of the regulatory $\mathrm{T}$ cell subtype that normally regulates inflammation (113). To further explore the underlying mechanisms of SLE, researchers have used mice that are characterized by the constitutive activation of the PI3K pathway in T lymphocytes and found that these mice develop SLE-like diseases (114). The increased activation of $\mathrm{mTORC} 1$ has also been reported in the $\mathrm{T}$ cells of patients suffering from multiple sclerosis (115). In a study on patients with rheumatoid arthritis, Zhang et al found significantly higher levels ( 4-fold) of p-Akt in fresh synovial tissue isolated from these patients (116). These findings highlight the central role of the Akt pathway in autoimmune diseases. It has been suggested that alterations in the PI3K/Akt axis found in highly active immune cells are mediated through metabolic changes in these cells (117).

Studies now focus on the therapeutic potency of molecules that target the PI3K/Akt pathway for the treatment of autoimmune diseases. Indeed, rapamycin, which inhibits the antigen-induced proliferation of $\mathrm{T}$ cells through the inhibition of $\mathrm{mTOR}$, has been shown to exert beneficial effects in experimental models and patients with autoimmune diseases $(118,119)$. Although there are several challenges that need to be tackled, the further exploration of this pathway may lead to the identification of disease biomarkers and therapeutic targets (120).

In Table I the main pathways that could be modulated by different molecules interfering with Akt signaling are reviewed.

\section{Repurposing studies}

Drug repositioning is a highly studied alternative using available drugs for the treatment of various conditions in order to discover novel therapeutic opportunities. This strategy is also used on the Akt pathway, capitalizing the lower toxicological risk of known drugs. Ivermectin is a macrocyclic lactone used as an antiparasitic drug that has been shown to significantly decrease Akt phosphorylation at Ser473. This result could allow its clinical investigation for cancer patients (121). Another 
Table I. Possible mechanism for Akt modulation used in clinical and preclinical settings.

Pathology models associated with Akt impairment

Malignant disease (carcinomas, glioblastoma, hematological malignancies, gastric carcinoma, glioblastomas and gliosarcomas, head and neck squamous cell carcinoma, pancreatic, ovarian, skin, prostate and breast cancers)
Signaling pathway injury

\author{
Molecules involved \\ in modulating \\ intracellular pathways
}

(Refs.)
Loss of PTEN activity, including
mutations involving PTEN
mutations activating the catalytic
subunit of PI3K, activation of RAS
and growth factor receptors,
amplification of the genes
encoding PI3K and Akt
impairment of proteins involved
in the Akt signaling pathway
impairment of PI3K/Akt/mTOR
regulated autophagy

\begin{abstract}
Elevated GSK-3 $\beta$ levels
(due to Akt inhibition)

overactivation of PTEN
\end{abstract}

(Alzheimer's, Parkinson's, and Huntington's disease, epilepsy and multiple sclerosis)

Insulin resistance, hyperinsulinemia, and glucose intolerance, diabetic polyneuropathy symptoms

Cardiovascular disease (vessel remodeling, atherosclerosis, etc.)

Idiopathic pulmonary fibrosis

\author{
Deletion of Akt2 \\ inhibition of PI3K-Akt \\ signaling PTEN activation \\ inhibition of PHLPP \\ Inhibition of Akt1 reduction \\ of Akt expression and \\ phosphorylation overexpression \\ of active FOXO3a \\ PTEN suppression \\ Activation of mTORC1
}

Isoquinoline-5-sulfonamides, azepane derivatives, aminofurazans, heterocyclic 6-5 fused rings, phenylpyrazoles, thiophenecarboxamides and derivatives 2,3-diphenylquinoxaline and analogs, alkylphospholipids, indole-3-carbinol derivatives, sulfonamides, thiourea deratives, and purine derivatives anti-inflammatory molecules (aspirin, celecoxib, meloxicam, or indomethacin) MK-2206

Lithium chloride okadaic acid

4H-chromene-3-carboxylate derivative (SC79), bisperoxovanadium compounds sulfuretin and vitexin

Vanadium compounds

Anticancer protein

$(91-93,95-97)$

kinase inhibitors

(ibrutinib and nilotinib)

Tubastatin

(98-100,

$(30,45,46$,

49-51,52-56)

(63-65,68,69, $70,75,76)$

Tubastatin
$101,103)$ antiparasitic drug, artesunate, may be useful in nasopharyngeal carcinoma by inhibiting Akt (122). Recent research has demonstrated the potential of propofol, an intravenous anesthetic drug, to be repurposed to overcome resistance to imatinib in chronic myeloid leukemia treatment (123). Cimetidine, a drug used in the treatment of peptic ulcers, induces the apoptotic death of cholangiocarcinoma cells by the suppression of Akt phosphorylation and may be an effective candidate for future treatments (124). A well-known antifungal agent, itraconazole, has demonstrated anticancer activity in various cell lines by inhibiting Akt/mTOR signaling (125). Quetiapine, an atypical antipsychotic, decreases the level of certain pro-inflammatory cytokines, such as interleukin (IL)-17, IL-6 and IL-1 $\beta$ in mouse model of arthritis by suppressing the Akt and Erk pathways (126).

\section{Natural products targeting the Akt pathway}

Plants and natural products are used as complementary or alternative therapies for cancer treatment, as a large number of patients consider them safer and less toxic $(127,128)$. Curcumin, the main curcuminoid found in Curcuma longa, has showed beneficial results regarding the inhibition of human malignant glioma cells by inducing autophagic cell death. The mechanisms implicated are the inhibition of the Akt/mTOR/p70S6K pathway and the activation of Erk1/2 pathway, and these have been demonstrated in in vitro and in vivo experiments (129). Lycopene, a carotenoid pigment found in tomatoes, has been shown to exert antitumorgenic effects on human colon cancer HT-29 cell lines, partly through the inhibition of Akt phosphorylation (130). Lupeol is a triterpenoid compound found in mango, dandelion and several other species of Acacia visco and Abronia villosa. Lupeol and its acetyl derivative have been shown to inhibit the proliferation and induce the apoptosis of human pancreatic cancer and chemoresistant prostate cancer cells by decreasing the levels of p-Akt and p-Erk (131). The chemically similar tirucallic acids isolated from the oleogum resin of Boswellia carterii inhibit Akt in prostate cancer cells by bonding within the PIP3 binding pocket (132).

As mentioned above, several flavonoid compounds, such as sulfuretin and apigenin, have been proven to target Akt. Jaceosidin 
is a flavone from Artemisia princeps, a traditional medicinal herb, with a marked effect on oral squamous cell carcinoma by Akt downregulation (133). The antiproliferative and antiinflammatory effect of luteolin via the inactivation of PI3K/Akt pathway has also been demonstrated by several studies $(134,135)$.

Euplotin $\mathrm{C}$ is a secondary metabolite of the marine ciliate Euplotes crassus that has demonstrated marked cytotoxic effects on human cutaneous melanoma cells via the inhibition of the Erk and Akt pathways (136). A large diversity of plant extracts have demonstrated promising anticancer properties in various cell lines, such as Libidibia ferrea and Celastrus orbiculatus in colorectal cancer $(137,138)$, Astragalus membranaceus, Anthriscus sylvestris and Vernonia amygdalina in breast cancer cells (139-141), Azadirachta indica in prostate cancer (142), and Fallopia aubertii and Fallopia convolvulus in cervical cancer cells (143), and these may represent future sources of leading Akt inhibitors. The usefulness of the natural sources is not limited to oncology. Bamboo leaf extract administered for a period of 12 weeks to diabetic rats has been shown to improve body weight and biochemical markers, and to alleviated renal injury by increasing p-Akt levels $(144,145)$. Similar properties were observed for sea buckthorn fruit oil extract and the traditional Chinese medicine Liuwei Dihaung $(146,147)$.

\section{Akt inhibitors in clinical studies}

Several compounds have been proven to inhibit Akt in in vitro and in vivo models, but only a small number have entered clinical evaluation, and yet no Akt inhibitor has been approved for anticancer therapy (148). Miltefosine is approved for the oral treatment of both visceral and cutaneous leishmaniasis, but not for oncological use (149).

GSK690693 was the first clinically evaluated Akt inhibitor. In preclinical experiments, GSK690693 was shown to inhibit all three isoforms at nanomolar concentrations and to significantly inhibit the growth of various tumors in mouse xenograft models. Despite the encouraging preclinical data, the clinical development of the agent was halted due to drug-related hyperglycemia and peripheral insulin resistance $(150,151)$.

AZD5363 is a pyrrolopyrimidine derivative that inhibits all Akt isoforms with nanomolar affinity, and inhibits the proliferation of a large number of solid and hematological tumor cell lines, with the highest therapeutical potential in breast cancer cells (152). The safety and tolerability of AZD5363 as oral monotherapy was evaluated in an open-label study (NCT01226316) on 90 patients with advanced solid malignancies. The patients received 320,480 or $640 \mathrm{mg}$ in a continuous or intermittent schedule. The most frequently reported adverse effects in all dosing schedules were diarrhea, nausea and vomiting. A total of $56(62 \%)$ patients experienced grade 3 adverse events, such as hyperglycemia (20\%), diarrhea (14\%) and rash $(11 \%)$. An adverse event leading to discontinuation was reported in $23 \%$ of the patients (153).

AZD5363 is under clinical evaluation as a short-term monotherapy in estrogen receptor-positive breast cancers (NCT02077569), and in non-small cell lung cancer (NCT02664935). It has been evaluated in combination with other anticancer drugs in various clinical trials $(153,154)$.

Ipatasertib belongs to the heterocyclic 6-5 fused rings class of ATP-competitive inhibitors. In a phase I study
(NCT01090960), the safety and tolerability in patients with refractory solid tumors was evaluated following orally administration of ipatasertib at daily doses from 25 to $800 \mathrm{mg}$. Ipatasertib was well tolerated, the most frequently reported adverse events of grade 2 or above were diarrhea $(35 \%)$, nausea $(27 \%)$, asthenia (25\%), hyperglycemia (10\%), decreased appetite $(6 \%)$, rash $(6 \%)$ and vomiting $(6 \%)$. The maximum tolerated dose (MTD) for ipatasertib is $600 \mathrm{mg}$ on a once daily, 21/7 dosing schedule (155).

The combination of ipatasertib (400 mg daily) and paclitaxel $\left(80 \mathrm{mg} / \mathrm{m}^{2}\right.$ weekly) was well-tolerated in a phase II study (NCT02301988) designed to estimate the efficacy in women with triple-negative breast cancer (42). A double-blind placebo controlled randomized phase II trial (NCT02162719) demonstrated that the combination modestly improved the progression-free survival endpoint, the results being prominent in the patients with PIK3CA/Akt1/PTEN alterations (156).

Afuresertib (GSK2110183) is a thiophenecarboxamide derivative, orally bioavailable Akt inhibitor, with higher potency against Akt1 compared to Akt2 and Akt3 (157). An open-label phase I clinical study (NCT00881946) evaluated afuresertib in 73 patients with advanced hematologic malignancies. All patients enrolled in the study experienced at least one adverse event, the most frequent being nausea, diarrhea, dyspepsia, fatigue, gastrointestinal reflux disease and anorexia. Treatment-related adverse events of grade 3 had a frequency under $10 \%$ and included neutropenia, rash, odynophagia, fatigue and asthenia, abnormal liver function test and thrombocytopenia. No grade 4 or 5 adverse events were observed. Afuresertib produced a small impact on glycaemia, due to the selectivity towards PKC (158). In a phase IIa study (NCT1395004), 17 patients with Langerhans cell histiocytosis received daily oral doses of $125 \mathrm{mg}$. The majority of the reported adverse events were grade 1 or 2 and consisted on nausea $(59 \%)$, fatigue $(53 \%)$, diarrhea $(47 \%)$ and upper respiratory infection (47\%) (159).

Uprosertib (GSK2141795) is closely related to afuresertib, the main difference being the replacement of the thiophene with a bioisostere furan ring (29). The safety, tolerability, pharmacokinetics, and pharmacodynamics of the drug were evaluated in a phase I, open-label study in patients with solid tumors. Uprosertib was safe and well-tolerated, most treatment-related adverse events were low grade and included diarrhea, fatigue, vomiting and decreased appetite (160).

MK-2206 is an orally effective, highly potent and selective allosteric pan-Akt inhibitor (150). Based on a phase I study of MK-2206 (NCT00670488) the MTD value was established at $60 \mathrm{mg}$ for an alternate days administration. Most frequent drug-related toxicities recorded were skin rash $(51.5 \%)$, nausea $(36.4 \%)$, pruritus $(24.2 \%)$, hyperglycemia $(21.2 \%)$ and diarrhea $(21.2 \%)$. The main dose limiting toxicity is a dose-dependent, generalized erythematous, nonblistering, maculopapular rash. This rash was observed also in other clinical trials with MK-2206 (161) and is similar to that produced by mTOR or PI3K inhibitors, but unlike those caused by epidermal growth factor receptor inhibitors indicating a mechanism-based toxicity, and not an off-target effect (162). It was investigated in several clinical trials. The potential use of MK-2206 goes beyond oncology, demonstrating a significant reduction of plasma LDL-cholesterol levels in cultured hepatic cells (163). 
Perifosine is an alkylphospholipid derivative that interferes with the PH domain of Akt rendering it incapable of phosphorylation and activation. Chemically, it resulted by replacing the choline moiety of miltefosine with a piperidine scaffold, leading to higher metabolic stabilityand better gastrointestinal tract tolerance because perifosine is not able to generate phosphocholine, responsible for the parasympathomimetic effects $(29,164)$. Clinical trials using oral perifosine as a single therapy for various types of cancer have produced disappointing results. Several combinations of perifosine are yielded promising results and are undergoing clinical development (165).

SR13668 was designed as an Akt activation inhibitor based on the naturally occurring indole-3-carbinol. In preclinical safety testing, no toxic effects were observed in rats after a single oral dose of $1,000 \mathrm{mg} / \mathrm{kg}$ or multiple doses of 25 up to $600 \mathrm{mg} / \mathrm{kg} /$ day for 14 days. In mice, doses up to $500 \mathrm{mg} / \mathrm{kg}$ had no effects on fasting glucose levels and body weight. It has a very low solubility which may hinder the future development of the drug $(166,167)$.

Triciribine (API-2, TCN, NSC 154020) is a tricyclic nucleoside that is metabolically activated inside cells by adenosine kinase to triciribine phosphate (TCN-P) which binds to the $\mathrm{PH}$ domain near PIP3 binding pocket, preventing PDK1 phosphorylation. TCN is highly selective towards Akt with no significant effect on PI3K, PKA or PKC $(168,169)$. The antitumor effects of TCN-P were known before the discovery of the Akt inactivation and were tested in several clinical trials. The therapeutic development of TCN-P limited by dose-limiting toxicities, including reversible hyperglycemia, hepatic toxicity, thrombocytopenia, hypocalcaemia and high triglyceride levels $(170,171)$. In order to circumvent the toxicities associated with TCN-P, the clinical development has focused on tumors that express high $\mathrm{p}-\mathrm{Akt}$ levels (172).

Miransertib (ARQ 092) binds to the inactive Akt and inhibits non-competitively all three isoforms at nanomolar concentrations and has excellent selectivity over other kinases (173). It is analyzed in several clinical trials for treatment as single therapy or combinations of advanced solid tumors and recurrent malignant lymphoma. Positive results were obtained with miransertib in cells and tissues harboring Akt1 E17K mutations and is being investigated for patients with overgrowth diseases and/or vascular anomalies generated by genetic alterations of the PI3K/AKT pathway (174). Miransertib is under study as a potential therapy for Proteus syndrome, a disease characterized by progressive and typically asymmetric overgrowth caused by the Akt1 E17K somatic activating mutation during development (175).

BAY 1125976 is a highly selective, potent allosteric Akt inhibitor by blocking the PDK1 phosphorylation after binding in the pocket formed by kinase and PH domain. Chemically it is a imidazo[1,2-b]pyridazine derivative, closely related to miransertib. It inhibits cell proliferation in a panel of human cancer cell lines, especially in hormone dependent breast and prostate cancer cell lines. It is under investigation is a phase I study (NCT01915576) in patients with advanced solid tumors (176).

\section{Conclusions}

Akt is the core of a complex signaling pathway that is one of the most intensively investigated cell signaling networks due to its crucial involvement in cell metabolism, growth, proliferation, motility, survival and apoptosis. These plethora of effects render Akt a most valuable target of drug discovery. Even if cancer treatment is at the center of the research, the potential applications are numerous other major diseases, such as diabetes, heart diseases, or neurodegenerative diseases. The position of Akt at the crossroads between life and death rises multiple challenges, but increasing understanding of cell biology and accumulating promising results are raising hope to find personalized treatments.

\section{Acknowledgements}

Not applicable.

\section{Funding}

No funding was received.

\section{Availability of data and materials}

Data sharing is not applicable to this article, as no datasets were generated or analyzed during the current study.

\section{Authors' contributions}

GMN, DMdV and AT were involved in the conception of the study. GMN, MVdV, GN, AU, PJ, QP, OTO, DG, AT, DT, DAS and DM were involved in the acquisition of the data and study design. GMN, MVdV, GN, AU, PJ, QP, OTO, DG, AT, DT, DAS and DM were involved in the writing of the article. GMN, DM, MVdV, PJ and DAS critically revised the manuscript. All authors have read and approved the final manuscript.

\section{Ethics approval and consent to participate}

Not applicable.

\section{Patient consent for publication}

Not applicable.

\section{Competing interests}

DAS is the Editor-in-Chief for the journal, but had no personal involvement in the reviewing process, or any influence in terms of adjudicating on the final decision, for this article.

\section{References}

1. Bellacosa A, de Feo D, Godwin AK, Bell DW, Cheng JQ, Altomare DA, Wan M, Dubeau L, Scambia G, Masciullo V, et al: Molecular alterations of the AKT2 oncogene in ovarian and breast carcinomas. Int J Cancer 64: 280-285, 1995.

2. Bellacosa A, Kumar CC and Di Cristofano A and Testa JR: Activation of AKT kinases in cancer: Implications for therapeutic targeting. Adv Cancer Res 94, 29-86, 2005.

3. Fresno Vara JA, Casado E, de Castro J, Cejas P, Belda-Iniesta C and González-Barón M: PI3K/Akt signalling pathway and cancer. Cancer Treat Rev 30: 193-204, 2004.

4. Zhao GX, Pan H, Ouyang DY and He XH: The critical molecular interconnections in regulating apoptosis and autophagy. Ann Med 47: 305-315, 2015. 
5. Duronio V: The life of a cell: Apoptosis regulation by the PI3K/PKB pathway. Biochem J 415: 333-344, 2008.

6. Song G, Ouyang $\mathrm{G}$ and Bao S: The activation of Akt/PKB signaling pathway and cell survival. J Cell Mol Med 9: 59-71, 2005.

7. Coffer PJ and Woodgett JR: Molecular cloning and characterisation of a novel putative protein-serine kinase related to the cAMPdependent and protein kinase C families. Eur J Biochem 201: 475-481, 1991.

8. Jones PF, Jakubowicz T, Pitossi FJ, Maurer F and Hemmings BA: Molecular cloning and identification of a serine/threonine protein kinase of the second-messenger subfamily. Proc Natl Acad Sci USA 88: 4171-4175, 1991

9. Bellacosa A, Testa J, Staal SP and Tsichlis PN: A retroviral oncogene, akt, encoding a serine-threonine kinase containing an SH2-like region. Science 254: 274-277, 1991.

10. Scheid MP and Woodgett JR: Unravelling the activation mechanisms of protein kinase B/Akt. FEBS Lett 546: 108-112, 2003.

11. Brazil DP, Yang ZZ and Hemmings BA: Advances in protein kinase B signalling: AKTion on multiple fronts. Trends Biochem Sci 29: 233-242, 2004.

12. Rodgers SJ, Ferguson DT, Mitchell CA and Ooms LM: Regulation of PI3K effector signalling in cancer by the phosphoinositide phosphatases. Biosci Rep 37: 37, 2017.

13. Dobbin ZC and Landen CN: The importance of the PI3K/AKT/ MTOR pathway in the progression of ovarian cancer. Int J Mol Sci 14: 8213-8227, 2013.

14. Ahmad A, Biersack B, Li Y, Kong D, Bao B, Schobert R, Padhye SB and Sarkar FH: Targeted regulation of PI3K/Akt/ $\mathrm{mTOR} / \mathrm{NF}-\kappa \mathrm{B}$ signaling by indole compounds and their derivatives: Mechanistic details and biological implications for cancer therapy. Anticancer Agents Med Chem 13: 1002-1013, 2013.

15. Montaño A, Forero-Castro M, Marchena-Mendoza D, Benito R and Hernández-Rivas JM: New Challenges in Targeting Signaling Pathways in Acute Lymphoblastic Leukemia by NGS Approaches: An Update. Cancers (Basel) 10: 10, 2018.

16. Altomare DA and Testa JR: Perturbations of the AKT signaling pathway in human cancer. Oncogene 24: 7455-7464, 2005.

17. Conus NM, Hannan KM, Cristiano BE, Hemmings BA and Pearson RB: Direct identification of tyrosine 474 as a regulatory phosphorylation site for the Akt protein kinase. J Biol Chem 277: 38021-38028, 2002.

18. Mora A, Komander D, van Aalten DMF and Alessi DR: PDK1, the master regulator of AGC kinase signal transduction. Semin Cell Dev Biol 15: 161-170, 2004.

19. Memmott RM and Dennis PA: Akt-dependent and -independent mechanisms of mTOR regulation in cancer. Cell Signal 21: 656-664, 2009

20. Jhaveri K and Modi S: Ganetespib: Research and clinical development. Onco Targets Ther 8: 1849-1858, 2015.

21. Georgescu MM: PTEN tumor suppressor network in PI3K-Akt pathway control. Genes Cancer 1: 1170-1177, 2010.

22. Hers I, Vincent EE and Tavaré JM: Akt signalling in health and disease. Cell Signal 23: 1515-1527, 2011.

23. Liu P, Cheng H, Roberts TM and Zhao JJ: Targeting the phosphoinositide 3-kinase pathway in cancer. Nat Rev Drug Discov 8: 627-644, 2009.

24. Hindupur SK, González A and Hall MN: The opposing actions of target of rapamycin and AMP-activated protein kinase in cell growth control. Cold Spring Harb Perspect Biol 7: a019141, 2015

25. Soliman GA: The role of mechanistic target of rapamycin (mTOR) complexes signaling in the immune responses. Nutrients 5 : 2231-2257, 2013

26. Laplante $M$ and Sabatini DM: mTOR signaling in growth control and disease. Cell 149: 274-293, 2012.

27. Sarbassov DD, Guertin DA, Ali SM and Sabatini DM: Phosphorylation and regulation of Akt/PKB by the rictor-mTOR complex. Science 307: 1098-1101, 2005.

28. Bozulic L and Hemmings BA: PIKKing on PKB: Regulation of PKB activity by phosphorylation. Curr Opin Cell Biol 21: 256-261, 2009.

29. Nitulescu GM, Margina D, Juzenas P, Peng Q, Olaru OT, Saloustros E, Fenga C, Spandidos DA, Libra $M$ and Tsatsakis AM: Akt inhibitors in cancer treatment: The long journey from drug discovery to clinical use (Review). Int J Oncol 48: 869-885, 2016

30. Inoki K, Li Y, Zhu T, Wu J and Guan KL: TSC2 is phosphorylated and inhibited by Akt and suppresses mTOR signalling. Nat Cell Biol 4: 648-657, 2002.

31. Hay N and Sonenberg N: Upstream and downstream of mTOR. Genes Dev 18: 1926-1945, 2004
32. Dowling RJ, Topisirovic I, Alain T, Bidinosti M, Fonseca BD, Petroulakis E, Wang X, Larsson O, Selvaraj A, Liu Y, et al: mTORC1-mediated cell proliferation, but not cell growth, controlled by the 4E-BPs. Science 328: 1172-1176, 2010.

33. Yu C, Li WB, Liu JB, Lu JW and Feng JF: Autophagy: Novel applications of nonsteroidal anti-inflammatory drugs for primary cancer. Cancer Med 7: 471-484, 2018.

34. Zhang X, Tang N, Hadden TJ and Rishi AK: Akt, FoxO and regulation of apoptosis. Biochim Biophys Acta 1813: 1978-1986, 2011.

35. Jin J, Jin L, Lim SW and Yang CW: Klotho deficiency aggravates tacrolimus-induced renal injury via the phosphatidylinositol 3-kinase-Akt-Forkhead box protein $\mathrm{O}$ pathway. Am J Nephrol 43: 357-365, 2016.

36. Ouyang ZH, Wang WJ, Yan YG, Wang B and Lv GH: The PI3K/Akt pathway: A critical player in intervertebral disc degeneration. Oncotarget 8: 57870-57881, 2017.

37. Pommier Y, Sordet O, Antony S, Hayward RL and Kohn KW: Apoptosis defects and chemotherapy resistance: Molecular interaction maps and networks. Oncogene 23: 2934-2949, 2004

38. Liao Y and Hung MC: Physiological regulation of Akt activity and stability. Am J Transl Res 2: 19-42, 2010.

39. Brognard J, Sierecki E, Gao T and Newton AC: PHLPP and a second isoform, PHLPP2, differentially attenuate the amplitude of Akt signaling by regulating distinct Akt isoforms. Mol Cell 25 : 917-931, 2007.

40. Newton AC and Trotman LC: Turning off AKT: PHLPP as a drug target. Annu Rev Pharmacol Toxicol 54: 537-558, 2014.

41. Haddadi N, Lin Y, Travis G, Simpson AM, Nassif NT and McGowan EM: PTEN/PTENP1: 'Regulating the regulator of RTK-dependent PI3K/Akt signalling', new targets for cancer therapy. Mol Cancer 17: 37, 2018.

42. Brown JS and Banerji U: Maximising the potential of AKT inhibitors as anti-cancer treatments. Pharmacol Ther 172: 101-115, 2017

43. Huck BR and Mochalkin I: Recent progress towards clinically relevant ATP-competitive Akt inhibitors. Bioorg Med Chem Lett 27: 2838-2848, 2017

44. Wang Q, Chen X and Hay N: Akt as a target for cancer therapy: More is not always better (lessons from studies in mice). Br J Cancer 117: 159-163, 2017.

45. Chalhoub $\mathrm{N}$ and Baker SJ: PTEN and the PI3-kinase pathway in cancer. Annu Rev Pathol 4: 127-150, 2009.

46. Nakatani K, Thompson DA, Barthel A, Sakaue H, Liu W, Weigel RJ and Roth RA: Up-regulation of Akt3 in estrogen receptor-deficient breast cancers and androgen-independent prostate cancer lines. J Biol Chem 274: 21528-21532, 1999.

47. Cristiano BE, Chan JC, Hannan KM, Lundie NA, Marmy-Conus NJ, Campbell IG, Phillips WA, Robbie M, Hannan RD and Pearson RB: A specific role for AKT3 in the genesis of ovarian cancer through modulation of $\mathrm{G}(2)-\mathrm{M}$ phase transition. Cancer Res 66: 11718-11725, 2006

48. Xia P and Xu XY: PI3K/Akt/mTOR signaling pathway in cancer stem cells: From basic research to clinical application. Am J Cancer Res 5: 1602-1609, 2015.

49. Milella M,Falcone I, Conciatori F, Cesta Incani U,Del Curatolo A, Inzerilli N, Nuzzo CM, Vaccaro V, Vari S, Cognetti F, et al: PTEN: Multiple functions in human malignant tumors. Front Oncol 5: 24, 2015.

50. Sato K, Tsuchihara K, Fujii S, Sugiyama M, Goya T, Atomi Y, Ueno T, Ochiai A, Esumi $\mathrm{H}$, et al: Autophagy is activated in colorectal cancer cells and contributes to the tolerance to nutrient deprivation. Cancer Res 67: 9677-9684, 2007.

51. Huang KH, Kuo KL, Ho IL, Chang HC, Chuang YT, Lin WC, Lee PY, Chang SC, Chiang CK, Pu YS, et al: Celecoxib-induced cytotoxic effect is potentiated by inhibition of autophagy in human urothelial carcinoma cells. PLoS One 8: e82034, 2013.

52. Bibbins-Domingo K; U.S. Preventive Services Task Force: Aspirin use for the primary prevention of cardiovascular disease and colorectal cancer: U.S. preventive services task force recommendation statement. Ann Intern Med 164: 836-845, 2016.

53. Zheng HC: The molecular mechanisms of chemoresistance in cancers. Oncotarget 8: 59950-59964, 2017.

54. Dasari S and Tchounwou PB: Cisplatin in cancer therapy: Molecular mechanisms of action. Eur J Pharmacol 740: 364-378, 2014.

55. Tao K, Yin Y, Shen Q, Chen Y, Li R, Chang W, Bai J, Liu W, Shi L and Zhang P: Akt inhibitor MK-2206 enhances the effect of cisplatin in gastric cancer cells. Biomed Rep 4: 365-368, 2016. 
56. Lin YH, Chen BYH, Lai WT, Wu SF, Guh JH, Cheng AL and Hsu LC: The Akt inhibitor MK-2206 enhances the cytotoxicity of paclitaxel (Taxol) and cisplatin in ovarian cancer cells. Naunyn Schmiedebergs Arch Pharmacol 388: 19-31, 2015.

57. Nagata Y, Lan KH, Zhou X, Tan M, Esteva FJ, Sahin AA, Klos KS, Li P, Monia BP, Nguyen NT, et al: PTEN activation contributes to tumor inhibition by trastuzumab, and loss of PTEN predicts trastuzumab resistance in patients. Cancer Cell 6: 117-127, 2004

58. Nahta R, Yu D, Hung MC, Hortobagyi GN and Esteva FJ: Mechanisms of disease: Understanding resistance to HER2targeted therapy in human breast cancer. Nat Clin Pract Oncol 3: 269-280, 2006

59. Crowell JA, Steele VE and Fay JR: Targeting the AKT protein kinase for cancer chemoprevention. Mol Cancer Ther 6 : 2139-2148, 2007.

60. Mayer IA and Arteaga CL: The PI3K/AKT pathway as a target for cancer treatment. Annu Rev Med 67: 11-28, 2016.

61. Geuna E, Roda D, Rafii S, Jimenez B, Capelan M, Rihawi K, Montemurro F, Yap TA, Kaye SB, De Bono JS, et al: Complications of hyperglycaemia with PI3K-AKT-mTOR inhibitors in patients with advanced solid tumours on Phase I clinical trials. Br J Cancer 113: 1541-1547, 2015

62. Ribeiro FM, Paquet M, Cregan SP and Ferguson SS: Group I metabotropic glutamate receptor signalling and its implication in neurological disease. CNS Neurol Disord Drug Targets 9: $574-595,2010$

63. Sattler R and Tymianski M: Molecular mechanisms of glutamate receptor-mediated excitotoxic neuronal cell death. Mol Neurobiol 24: 107-129, 2001.

64. Baskys A, Bayazitov I, Fang L, Blaabjerg M, Poulsen FR and Zimmer J: Group I metabotropic glutamate receptors reduce excitotoxic injury and may facilitate neurogenesis. Neuropharmacology 49 (Suppl 1): 146-156, 2005.

65. Costa C, Tsatsakis A, Mamoulakis C, Teodoro M, Briguglio G, Caruso E, Tsoukalas D, Margina D, Dardiotis E, Kouretas D, et al: Current evidence on the effect of dietary polyphenols intake on chronic diseases. Food Chem Toxicol 110: 286-299, 2017.

66. Reddy PH: Amyloid beta-induced glycogen synthase kinase $3 \beta$ phosphorylated VDAC1 in Alzheimer's disease: implications for synaptic dysfunction and neuronal damage. Biochim Biophys Acta 1832: 1913-1921, 2013.

67. Hernandez F, Lucas JJ and Avila J: GSK3 and tau: Two convergence points in Alzheimer's disease. J Alzheimers Dis 3 (Suppl 1): 141-144, 2012.

68. Li X, Lu F, Tian Q, Yang Y, Wang Q and Wang JZ: Activation of glycogen synthase kinase-3 induces Alzheimer-like tau hyperphosphorylation in rat hippocampus slices in culture. J Neural Transm (Vienna) 113: 93-102, 2006.

69. Luo HR, Hattori H, Hossain MA, Hester L, Huang Y, Lee-Kwon W, Donowitz M, Nagata E and Snyder SH: Akt as a mediator of cell death. Proc Natl Acad Sci USA 100: 11712-11717, 2003

70. Wang R and Reddy PH: Role of glutamate and NMDA receptors in Alzheimer's disease. J Alzheimers Dis 57: 1041-1048, 2017.

71. Ferrarelli LK: PTEN contributes to Alzheimer's disease. Sci Signal 9: ec45, 2016

72. Frere S and Slutsky I: Targeting PTEN interactions for Alzheimer's disease. Nat Neurosci 19: 416-418, 2016.

73. Chen Z, Chen B, Xu WF, Liu RF, Yang J and Yu CX: Effects of PTEN inhibition on regulation of tau phosphorylation in an okadaic acid-induced neurodegeneration model. Int J Dev Neurosci 30: 411-419, 2012

74. Jo H, Mondal S, Tan D, Nagata E, Takizawa S, Sharma AK, Hou Q, Shanmugasundaram K, Prasad A, Tung JK, et al: Smal molecule-induced cytosolic activation of protein kinase Akt rescues ischemia-elicited neuronal death. Proc Natl Acad Sci USA 109: 10581-10586, 2012.

75. Pulido R: PTEN inhibition in human disease therapy. Molecules 23: E285, 2018.

76. Mhyre TR, Boyd JT, Hamill RW and Maguire-Zeiss KA: Parkinson's disease. Subcell Biochem 65: 389-455, 2012.

77. Xu Y, Gao YW and Yang Y: SC79 protects dopaminergic neurons from oxidative stress. Oncotarget 9: 12639-12648, 2017.

78. Pariyar R, Lamichhane R, Jung HJ, Kim SY and Seo J: Sulfuretin attenuates $\mathrm{MPP}^{+}$-induced neurotoxicity through $\mathrm{Akt} / \mathrm{GSK} 3 \beta$ and ERK signaling pathways. Int J Mol Sci 18: E2753, 2017

79. $\mathrm{Hu} \mathrm{M}, \mathrm{Li} \mathrm{F}$ and Wang W: Vitexin protects dopaminergic neurons in MPTP-induced Parkinson's disease through PI3K/Akt signaling pathway. Drug Des Devel Ther 12: 565-573, 2018.
80. Masaki K and Douglas Z: Diabetic neuropathy and the sensory neuron: New aspects of pathogenesis and their treatment implications. J Diabetes Investig: Mar 13, 2018 (Epub ahead of print). doi: $10.1111 /$ jdi.12833.

81. Boucher J, Kleinridders A and Kahn CR: Insulin receptor signaling in normal and insulin-resistant states. Cold Spring Harb Perspect Biol 6: a009191, 2014.

82.Zaid H, Antonescu CN, Randhawa VK and Klip A: Insulin action on glucose transporters through molecular switches, tracks and tethers. Biochem J 413: 201-215, 2008.

83. Lim CY, Bi X, Wu D, Kim JB, Gunning PW, Hong W and Han W: Tropomodulin3 is a novel Akt2 effector regulating insulin-stimulated GLUT4 exocytosis through cortical actin remodeling. Nat Commun 6: 5951, 2015.

84. Cho H, Mu J, Kim JK, Thorvaldsen JL, Chu Q, Crenshaw EB III, Kaestner KH, Bartolomei MS, Shulman GI, Birnbaum MJ: Insulin resistance and a diabetes mellitus-like syndrome in mice lacking the protein kinase Akt2 (PKB beta). Science 292. $1728-1731,2001$

85. Gradinaru D, Khaddour H, Margina D, Ungurianu A, Borsa C, Ionescu C, Prada GI, Usher J and Elshimali Y: Insulin-leptin axis, cardiometabolic risk and oxidative stress in elderly with metabolic syndrome. Exp Clin Endocrinol Diabetes 126: 445-452, 2018

86. Koren S, DiPilato LM, Emmett MJ, Shearin AL, Chu Q, Monks B and Birnbaum MJ: The role of mouse Akt 2 in insulin-dependent suppression of adipocyte lipolysis in vivo. Diabetologia 58: 1063-1070, 2015.

87. Hussain K, Challis B, Rocha N, Payne F, Minic M, Thompson A, Daly A, Scott C, Harris J, Smillie BJ, et al: An activating mutation of AKT2 and human hypoglycemia. Science 334: 474, 2011.

88. Badea M, Olar R, Uivarosi V, Marinescu D, Aldea V, Barbuceanu SF and Nitulescu GM: Thermal behavior of some vanadyl complexes with flavone derivatives as potential insulinmimetic agents. J Therm Anal Calorim 105: 105, 2011

89. Domingo JL and Gómez M: Vanadium compounds for the treatment of human diabetes mellitus: A scientific curiosity? A review of thirty years of research. Food Chem Toxicol 95: 137-141, 2016.

90. Sierecki E, Sinko W, McCammon JA and Newton AC: Discovery of small molecule inhibitors of the $\mathrm{PH}$ domain leucine-rich repeat protein phosphatase (PHLPP) by chemical and virtual screening. J Med Chem 53: 6899-6911, 2010.

91.Zhao W and Zhao SP: Different effects of statins on induction of diabetes mellitus: An experimental study. Drug Des Devel Ther 9: 6211-6223, 2015.

92. Bonifacio A, Sanvee GM, Bouitbir J and Krähenbühl S: The AKT/mTOR signaling pathway plays a key role in statin-induced myotoxicity. Biochim Biophys Acta 1853: 1841-1849, 2015.

93. Beckwitt CH, Shiraha K and Wells A: Lipophilic statins limit cancer cell growth and survival, via involvement of Akt signaling. PLoS One 13: e0197422, 2018.

94. Yu H, Littlewood T and Bennett M: Akt isoforms in vascular disease. Vascul Pharmacol 71: 57-64, 2015.

95. Rotllan N, Chamorro-Jorganes A, Araldi E, Wanschel AC, Aryal B, Aranda JF, Goedeke L, Salerno AG, Ramírez CM, Sessa WC, et al: Hematopoietic Akt2 deficiency attenuates the progression of atherosclerosis. FASEB J 29: 597-610, 2015

96. Yao S, Fan LY and Lam EW: The FOXO3-FOXM1 axis: A key cancer drug target and a modulator of cancer drug resistance. Semin Cancer Biol 50: 77-89, 2018.

97. Dhalla NS and Müller AL: Protein kinases as drug development targets for heart disease therapy. Pharmaceuticals (Basel) 3 $2111-2145,2010$

98. McMullen JR, Boey EJ, Ooi JY, Seymour JF, Keating MJ and Tam CS: Ibrutinib increases the risk of atrial fibrillation, potentially through inhibition of cardiac PI3K-Akt signaling. Blood 124: 3829-3830, 2014.

99. Pretorius L, Du XJ, Woodcock EA, Kiriazis H, Lin RC, Marasco S, Medcalf RL, Ming Z, Head GA, Tan JW, et al: Reduced phosphoinositide 3-kinase (p110 $\alpha$ ) activation increases the susceptibility to atrial fibrillation. Am J Pathol 175 998-1009, 2009.

100. Ezeani M and Elom S: Necessity to evaluate PI3K/Akt signalling pathway in proarrhythmia. Open Hear 4: e000596, 2017.

101. Tamura M, Gu J, Danen EHJ, Takino T, Miyamoto S and Yamada KM: PTEN interactions with focal adhesion kinase and suppression of the extracellular matrix-dependent phosphatidylinositol 3-kinase/Akt cell survival pathway. J Biol Chem 274: 20693-20703, 1999. 
102. Nho RS, Hergert P, Kahm J, Jessurun J and Henke C: Pathological alteration of FoxO3a activity promotes idiopathic pulmonary fibrosis fibroblast proliferation on type i collagen matrix. Am J Pathol 179: 2420-2430, 2011.

103. Lawrence J and Nho R: The Role of the Mammalian Target of Rapamycin (mTOR) in Pulmonary Fibrosis. Int J Mol Sci 19: 778, 2018.

104. Xia H, Khalil W, Kahm J, Jessurun J, Kleidon J and Henke CA: Pathologic caveolin-1 regulation of PTEN in idiopathic pulmonary fibrosis. Am J Pathol 176: 2626-2637, 2010.

105. Nho RS, Peterson M, Hergert P and Henke CA: FoxO3a (Forkhead Box O3a) deficiency protects Idiopathic Pulmonary Fibrosis (IPF) fibroblasts from type I polymerized collagen matrix-induced apoptosis via caveolin-1 (cav-1) and Fas. PLoS One 8: e61017, 2013.

106. Lu Y, Azad N, Wang L, Iyer AKV, Castranova V, Jiang BH and Rojanasakul Y: Phosphatidylinositol-3-kinase/akt regulates bleomycin-induced fibroblast proliferation and collagen production. Am J Respir Cell Mol Biol 42: 432-441, 2010.

107. Saito S, Zhuang Y, Shan B, Danchuk S, Luo F, Korfei M, Guenther A and Lasky JA: Tubastatin ameliorates pulmonary fibrosis by targeting the TGF $\beta$-PI3K-Akt pathway. PLoS One 12: e0186615, 2017.

108. Theofilopoulos AN, Kono DH and Baccala R: The multiple pathways to autoimmunity. Nat Immunol 18: 716-724, 2017.

109. Goodnow CC, Crosbie J, Adelstein S, Lavoie TB, Smith-Gill SJ, Brink RA, Pritchard-Briscoe H, Wotherspoon JS, Loblay RH, Raphael K, et al: Altered immunoglobulin expression and functional silencing of self-reactive B lymphocytes in transgenic mice. Nature 334: 676-682, 1988.

110. Sakaguchi S: Naturally arising Foxp3-expressing CD $25^{+} \mathrm{CD} 4^{+}$ regulatory $\mathrm{T}$ cells in immunological tolerance to self and non-self. Nat Immunol 6: 345-352, 2005.

111. Matthews R: Autoimmune diseases. The B cell slayer. Science 318: 1232-1233, 2007.

112. Waldman M and Madaio MP: Pathogenic autoantibodies in lupus nephritis. Lupus 14: 19-24, 2005.

113. Lai ZW, Borsuk R, Shadakshari A, Yu J, Dawood M, Garcia R, Francis L, Tily H, Bartos A, Faraone SV, et al: Mechanistic target of rapamycin activation triggers IL-4 production and necrotic death of double-negative T cells in patients with systemic lupus erythematosus. J Immunol 191: 2236-2246, 2013.

114. Di Cristofano A, Kotsi P, Peng YF, Cordon-Cardo C, Elkon KB and Pandolfi PP: Impaired Fas response and autoimmunity in $\mathrm{Pten}^{+/}$mice. Science 285: 2122-2125, 1999.

115. Carbone F, De Rosa V, Carrieri PB, Montella S, Bruzzese D, Porcellini A, Procaccini C, La Cava A and Matarese G: Regulatory T cell proliferative potential is impaired in human autoimmune disease. Nat Med 20: 69-74, 2014.

116. Zhang HG, Wang Y, Xie JF, Liang X, Liu D, Yang P, Hsu HC, Ray RB and Mountz JD: Regulation of tumor necrosis factor $\alpha$-mediated apoptosis of rheumatoid arthritis synovial fibroblasts by the protein kinase Akt. Arthritis Rheum 44: 1555-1567, 2001.

117. Chimenti MS, Triggianese P, Conigliaro P, Candi E, Melino G and Perricone R: The interplay between inflammation and metabolism in rheumatoid arthritis. Cell Death Dis 6: e1887,2015.

118. Warner LM, Adams LM and Sehgal SN: Rapamycin prolongs survival and arrests pathophysiologic changes in murine systemic lupus erythematosus. Arthritis Rheum 37: 289-297, 1994.

119. Fernandez D, Bonilla E, Mirza N, Niland B and Perl A: Rapamycin reduces disease activity and normalizes $\mathrm{T}$ cell activation-induced calcium fluxing in patients with systemic lupus erythematosus. Arthritis Rheum 54: 2983-2988, 2006.

120. Wu T and Mohan C: The AKT axis as a therapeutic target in autoimmune diseases. Endocr Metab Immune Disord Drug Targets 9: 145-150, 2009.

121. Juarez M, Schcolnik-Cabrera A and Dueñas-Gonzalez A: The multitargeted drug ivermectin: From an antiparasitic agent to a repositioned cancer drug. Am J Cancer Res 8: 317-331, 2018

122. Li Q, Ni W, Deng Z, Liu M, She L and Xie Q: Targeting nasopharyngeal carcinoma by artesunate through inhibiting Akt/mTOR and inducing oxidative stress. Fundam Clin Pharmacol 31: 301-310, 2017.

123.Tan Z, Peng A, Xu J and Ouyang M: Propofol enhances BCR-ABL TKIs' inhibitory effects in chronic myeloid leukemia through Akt/mTOR suppression. BMC Anesthesiol 17: 132, 2017.

124.Dana P, Vaeteewoottacharn K, Kariya R, Matsuda K, Wongkham S and Okada S: Repurposing cimetidine for cholangiocarcinoma: Antitumor effects in vitro and in vivo. Oncol Lett 13: 1432-1436, 2017.
125. Tsubamoto $H$, Inoue $K$, Sakata $K$, Ueda T, Takeyama R, Shibahara $\mathrm{H}$ and Sonoda T: Itraconazole inhibits AKT/ mTOR signaling and proliferation in endometrial cancer cells. Anticancer Res 37: 515-519, 2017.

126. Pan YJ, Wang WH, Huang TY, Weng WH, Fang CK, Chen YC and Hwang JJ: Quetiapine ameliorates collagen-induced arthritis in mice via the suppression of the AKT and ERK signaling pathways. Inflamm Res 67: 847-861, 2018.

127. Margină D, Ilie M, Grădinaru D, Androutsopoulos VP, Kouretas D and Tsatsakis AM: Natural products-friends or foes? Toxicol Lett 236: 154-167, 2015.

128. Seca AML and Pinto DCGA: Plant secondary metabolites as anticancer agents: Successes in clinical trials and therapeutic application. Int J Mol Sci 19: 263, 2018

129. Aoki H, Takada Y, Kondo S, Sawaya R, Aggarwal BB and Kondo Y: Evidence that curcumin suppresses the growth of malignant gliomas in vitro and in vivo through induction of autophagy: Role of Akt and extracellular signal-regulated kinase signaling pathways. Mol Pharmacol 72: 29-39, 2007.

130. Tang FY, Shih CJ, Cheng LH, Ho HJ and Chen HJ: Lycopene inhibits growth of human colon cancer cells via suppression of the Akt signaling pathway. Mol Nutr Food Res 52: 646-654, 2008.

131. Schmidt C, Loos C, Jin L, Schmiech M, Schmidt CQ, Gaafary ME, Syrovets T and Simmet T: Acetyl-lupeolic acid inhibits Akt signaling and induces apoptosis in chemoresistant prostate cancer cells in vitro and in vivo. Oncotarget 8: 55147-55161, 2017.

132. Estrada AC, Syrovets T, Pitterle K, Lunov O, Büchele B, Schimana-Pfeifer J, Schmidt T, Morad SA and Simmet T: Tirucallic acids are novel pleckstrin homology domaindependent Akt inhibitors inducing apoptosis in prostate cancer cells. Mol Pharmacol 77: 378-387, 2010.

133. Han HY, Kim HJ, Jeong SH, Kim J, Jeong SH, Kim GC, Hwang DS, Kim UK and Ryu MH: The flavonoid Jaceosidin from Artemisia princeps induces apoptotic cell death and inhibits the Akt pathway in oral cancer cells. Evid Based Complement Alternat Med 2018: 5765047, 2018.

134. Lin CH, Chang CY, Lee KR, Lin HJ, Chen TH and Wan L: Flavones inhibit breast cancer proliferation through the Akt/FOXO3a signaling pathway. BMC Cancer 15: 958, 2015.

135.Lim W, Yang C, Bazer FW and Song G: Luteolin inhibits proliferation and induces apoptosis of human placental choriocarcinoma cells by blocking the PI3K/AKT pathway and regulating sterol regulatory element binding protein activity. Biol Reprod 95: 82, 2016.

136. Carpi S, Polini B, Poli G, Alcantara Barata G, Fogli S, Romanini A, Tuccinardi T, Guella G, Frontini FP, Nieri P, et al: Anticancer activity of euplotin $\mathrm{C}$, isolated from the marine ciliate Euplotes crassus, against human melanoma cells. Mar Drugs 16: E166, 2018.

137. Guerra AC, Soares LA, Ferreira MR, Araújo AA, Rocha HA, Medeiros JS, Cavalcante RD and Júnior RF: Libidibia ferrea presents antiproliferative, apoptotic and antioxidant effects in a colorectal cancer cell line. Biomed Pharmacother 92: 696-706, 2017.

138. Yang L, Liu Y, Wang M, Qian Y, Dai X, Zhu Y, Chen J, Guo $S$ and Hisamitsu T: Celastrus orbiculatus extract triggers apoptosis and autophagy via PI3K/Akt/mTOR inhibition in human colorectal cancer cells. Oncol Lett 12: 3771-3778, 2016.

139. Zhou R, Chen H, Chen J, Chen X, Wen Y and Xu L: Extract from Astragalus membranaceus inhibit breast cancer cells proliferation via PI3K/AKT/mTOR signaling pathway. BMC Complement Altern Med 18: 83, 2018.

140. Wong FC, Woo CC, Hsu A and Tan BKH: The anti-cancer activities of Vernonia amygdalina extract in human breast cancer cell lines are mediated through caspase-dependent and p53-independent pathways. PLoS One 8: e78021, 2013.

141. Olaru OT, Niţulescu GM, Orțan A and Dinu-Pîrvu CE: Ethnomedicinal, phytochemical and pharmacological profile of anthriscus sylvestris as an alternative source for anticancer lignans. Molecules 20: 15003-15022, 2015.

142. Gunadharini DN, Elumalai P, Arunkumar R, Senthilkumar K and Arunakaran J: Induction of apoptosis and inhibition of $\mathrm{PI} 3 \mathrm{~K} / \mathrm{Akt}$ pathway in PC-3 and LNCaP prostate cancer cells by ethanolic neem leaf extract. J Ethnopharmacol 134: 644-650, 2011.

143. Olaru OT, Venables L, VAN DE Venter M, Nitulescu GM, Margina D, Spandidos DA and Tsatsakis AM: Anticancer potential of selected Fallopia Adans species. Oncol Lett 10: 1323-1332, 2015. 
144. Ying C, Mao Y, Chen L, Wang S, Ling H, Li W and Zhou X: Bamboo leaf extract ameliorates diabetic nephropathy through activating the AKT signaling pathway in rats. Int $\mathrm{J}$ Biol Macromol 105: 1587-1594, 2017.

145.Lu Q, Zuo WZ, Ji XJ, Zhou YX, Liu YQ, Yao XQ, Zhou XY, Liu YW, Zhang F and Yin XX: Ethanolic Ginkgo biloba leaf extract prevents renal fibrosis through Akt/mTOR signaling in diabetic nephropathy. Phytomedicine 22: 1071-1078, 2015.

146.Dai B, Wu Q, Zeng C, Zhang J, Cao L, Xiao Z and Yang M: The effect of Liuwei Dihuang decoction on PI3K/Akt signaling pathway in liver of type 2 diabetes mellitus (T2DM) rats with insulin resistance. J Ethnopharmacol 192: 382-389, 2016

147. Gao S, Guo Q, Qin C, Shang R and Zhang Z: Sea buckthorn fruit oil extract alleviates insulin resistance through the PI3K/Akt signaling pathway in type 2 diabetes mellitus cells and rats. J Agric Food Chem 65: 1328-1336, 2017.

148. Mundi PS, Sachdev J, McCourt C and Kalinsky K: AKT in cancer: New molecular insights and advances in drug development. Br J Clin Pharmacol 82: 943-956, 2016.

149. Dorlo TP, Balasegaram M, Beijnen JH and de Vries PJ: Beijnen JH and de vries PJ: Miltefosine: A review of its pharmacology and therapeutic efficacy in the treatment of leishmaniasis. J Antimicrob Chemother 67: 2576-2597, 2012

150.Pal SK, Reckamp K, Yu H and Figlin RA: Akt inhibitors in clinical development for the treatment of cancer. Expert Opin Investig Drugs 19: 1355-1366, 2010.

151. Mattmann ME, Stoops SL and Lindsley CW: Inhibition of Akt with small molecules and biologics: Historical perspective and current status of the patent landscape. Expert Opin Ther Pat 21 1309-1338, 2011.

152. Davies BR, Greenwood H, Dudley P, Crafter C, Yu DH, Zhang J, Li J, Gao B, Ji Q, Maynard J, et al: Preclinical pharmacology of AZD5363, an inhibitor of AKT: Pharmacodynamics, antitumor activity, and correlation of monotherapy activity with genetic background. Mol Cancer Ther 11: 873-887, 2012.

153. Banerji U, Dean EJ, Pérez-Fidalgo JA, Batist G, Bedard PL, You B, Westin SN, Kabos P, Garrett MD, Tall M, et al: A phase I open-label study to identify a dosing regimen of the Pan-AKT inhibitor AZD5363 for evaluation in solid tumors and in PIK3CA-mutated breast and gynecologic cancers. Clin Cancer Res 24: 2050-2059, 2018.

154. Sundar R, Chénard-Poirier M, Collins DC and Yap TA: Imprecision in the era of precision medicine in non-small cell lung cancer. Front Med (Lausanne) 4: 39, 2017.

155. Saura C, Roda D, Roselló S, Oliveira M, Macarulla T, Pérez-Fidalgo JA, Morales-Barrera R, Sanchis-García JM, Musib L, Budha N, et al: A first-in-human phase I study of the ATP-competitive AKT inhibitor ipatasertib demonstrates robust and safe targeting of AKT in patients with solid tumors. Cancer Discov 7: 102-113, 2017.

156. Dent RA, Kim SB, Im SA, Espie M, Blau S, Tan AR, Isakoff S, Oliveira M, Saura C, Wongchenko M, et al: LOTUS (NCT02162719): A double-blind placebo (PBO)-controlled randomized phase II trial of first-line ipatasertib (IPAT) + paclitaxel $(\mathrm{P})$ for metastatic triple-negative breast cancer (TNBC). J Clin Oncol 35 (Suppl 15): 1009, 2017.

157. Dumble M, Crouthamel M-C, Zhang S-Y, Schaber M, Levy D, Robell K, Liu Q, Figueroa DJ, Minthorn EA, Seefeld MA, et al: Discovery of novel AKT inhibitors with enhanced anti-tumor effects in combination with the MEK inhibitor. PLoS One 9: e100880, 2014.

158. Spencer A, Yoon SS, Harrison SJ, Morris SR, Smith DA Brigandi RA, Gauvin J, Kumar R, Opalinska JB and Chen C: The novel AKT inhibitor afuresertib shows favorable safety, pharmacokinetics, and clinical activity in multiple myeloma. Blood 124: 2190-2195, 2014.

159. Arceci RJ, Allen CE, Dunkel IJ, Jacobsen E, Whitlock J, Vassallo R, Morris SR, Portnoy A, Reedy BA, Smith DA, et al: A phase IIa study of afuresertib, an oral pan-AKT inhibitor in patients with Langerhans cell histiocytosis. Pediatr Blood Cancer 64: 64, 2017.

160. Aghajanian C, Bell-McGuinn KM, Burris HA III, Siu LL, Stayner LA, Wheler JJ, Hong DS, Kurkjian C, Pant S, Santiago-Walker A, et al: A phase I, open-label, two-stage study to investigate the safety, tolerability, pharmacokinetics, and pharmacodynamics of the oral AKT inhibitor GSK2141795 in patients with solid tumors. Invest New Drugs: Apr 3, 2018. (Epub ahead of print). doi: 10.1007/s10637-018$0591-\mathrm{z}$.
161. Ma BB, Goh BC, Lim WT, Hui EP, Tan EH, Lopes GL, Lo KW, Li L, Loong H, Foster NR, et al: Multicenter phase II study of the AKT inhibitor MK-2206 in recurrent or metastatic nasopharyngeal carcinoma from patients in the mayo phase II consortium and the cancer therapeutics research group (MC1079). Invest New Drugs 33: 985-991, 2015.

162. Yap TA, Yan L, Patnaik A, Fearen I, Olmos D, Papadopoulos K, Baird RD, Delgado L, Taylor A, Lupinacci L, et al: First-in-man clinical trial of the oral pan-AKT inhibitor MK-2206 in patients with advanced solid tumors. J Clin Oncol 29: 4688-4695, 2011.

163. Bjune K, Sundvold H, Leren TP and Naderi S: MK-2206, an allosteric inhibitor of AKT, stimulates LDLR expression and LDL uptake: A potential hypocholesterolemic agent. Atherosclerosis 276: 28-38, 2018.

164. Richardson PG, Eng C, Kolesar J, Hideshima T and Anderson KC: Perifosine, an oral, anti-cancer agent and inhibitor of the Akt pathway: Mechanistic actions, pharmacodynamics, pharmacokinetics, and clinical activity. Expert Opin Drug Metab Toxicol 8: 623-633, 2012

165. Ríos-Marco P, Marco C, Gálvez X, Jiménez-López JM and Carrasco MP: Alkylphospholipids: An update on molecular mechanisms and clinical relevance. Biochim Biophys Acta Biomembr 1859: 1657-1667, 2017.

166. Reid JM, Walden CA, Qin R, Ziegler KL, Haslam JL, Rajewski RA, Warndahl R, Fitting CL, Boring D, Szabo E, et al; Cancer Prevention Network: Phase 0 clinical chemoprevention trial of the Akt inhibitor SR13668. Cancer Prev Res (Phila) 4: 347-353, 2011.

167. Kapetanovic IM, Muzzio M, Hu SC, Crowell JA, Rajewski RA, Haslam JL, Jong L and McCormick DL: Pharmacokinetics and enhanced bioavailability of candidate cancer preventative agent, SR13668 in dogs and monkeys. Cancer Chemother Pharmacol 65: 1109-1116, 2010

168. Yang L, Dan HC, Sun M, Liu Q, Sun XM, Feldman RI, Hamilton AD, Polokoff M, Nicosia SV, Herlyn M, et al: Akt/protein kinase B signaling inhibitor-2, a selective small molecule inhibitor of Akt signaling with antitumor activity in cancer cells overexpressing Akt. Cancer Res 64: 4394-4399, 2004.

169. Berndt N, Yang H, Trinczek B, Betzi S, Zhang Z, Wu B, Lawrence NJ, Pellecchia M, Schönbrunn E, Cheng JQ, et al: The Akt activation inhibitor TCN-P inhibits Akt phosphorylation by binding to the $\mathrm{PH}$ domain of Akt and blocking its recruitment to the plasma membrane. Cell Death Differ 17: 1795-1804, 2010.

170. Hoffman K, Holmes FA, Fraschini G, Esparza L, Frye D, Raber MN, Newman RA and Hortobagyi GN: Phase I-II study: Triciribine (tricyclic nucleoside phosphate) for metastatic breast cancer. Cancer Chemother Pharmacol 37: 254-258, 1996.

171. Feun LG, Savaraj N, Bodey GP, Lu K, Yap BS, Ajani JA, Burgess MA, Benjamin RS, McKelvey E and Krakoff I: Phase I study of tricyclic nucleoside phosphate using a five-day continuous infusion schedule. Cancer Res 44: 3608-3612, 1984

172. Sampath D, Malik A, Plunkett W, Nowak B, Williams B, Burton M, Verstovsek S, Faderl S, Garcia-Manero G, List AF, et al: Phase I clinical, pharmacokinetic, and pharmacodynamic study of the Akt-inhibitor triciribine phosphate monohydrate in patients with advanced hematologic malignancies. Leuk Res 37: 1461-1467, 2013

173. Kim K, Li J, Barazia A, Tseng A, Youn SW, Abbadessa G, Yu Y, Schwartz B, Andrews RK, Gordeuk VR, et al: ARQ 092, an orally-available, selective AKT inhibitor, attenuates neutrophilplatelet interactions in sickle cell disease. Haematologica 102: 246-259, 2017

174. Ranieri C, Di Tommaso S, Loconte DC, Grossi V, Sanese P, Bagnulo R, Susca FC, Forte G, Peserico A, De Luisi A, et al: In vitro efficacy of ARQ 092, an allosteric AKT inhibitor, on primary fibroblast cells derived from patients with PIK3CA-related overgrowth spectrum (PROS). Neurogenetics 19: 77-91, 2018

175. Lindhurst MJ, Yourick MR, Yu Y, Savage RE, Ferrari D and Biesecker LG: Repression of AKT signaling by ARQ 092 in cells and tissues from patients with Proteus syndrome. Sci Rep 5: 17162, 2015.

176. Politz O, Siegel F, Bärfacker L, Bömer U, Hägebarth A, Scott WJ, Michels M, Ince S, Neuhaus R, Meyer K, et al: BAY 1125976, a selective allosteric AKT1/2 inhibitor, exhibits high efficacy on AKT signaling-dependent tumor growth in mouse models. Int J Cancer 140: 449-459, 2017

This work is licensed under a Creative Commons

Attribution-NonCommercial-NoDerivatives 4.0 International (CC BY-NC-ND 4.0) License. 